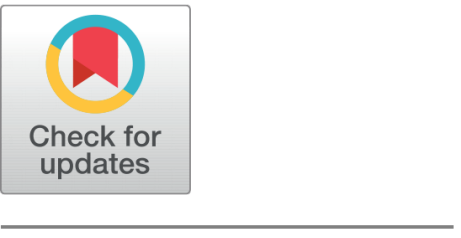

OPEn ACCESS

Received: 30.09 .2020

Accepted: 06.12.2020

Published: 18.12 .2020

Citation: Al-Rawi M, Sharma C, Zhou H (2020) Optimization of pipeline reducer using computational fluid dynamics (CFD) modelling. Indian Journal of Science and Technology 13(45): 4521-4531. https://doi.org/

10.17485/IJST/v13i45.1911

* Corresponding author.

mohammad.al-rawi@wintec.ac.nz

Funding: None

Competing Interests: None

Copyright: (๐ 2020 Al-Rawi et al. This is an open access article distributed under the terms of the Creative Commons Attribution License, which permits unrestricted use, distribution, and reproduction in any medium, provided the original author and source are credited.

Published By Indian Society for Education and Environment (iSee)

ISSN

Print: 0974-6846

Electronic: 0974-5645

\section{Optimization of pipeline reducer using computational fluid dynamics (CFD) modelling}

\author{
Mohammad Al-Rawi ${ }^{1}$, Chetan Sharma ${ }^{2}$, Hong Zhou ${ }^{1}$ \\ 1 Centre for Engineering and Industrial Design (CEID)/ Waikato Institute of Technology \\ (Wintec), Hamilton 3240, New Zealand \\ 2 Strata Precision Plastics Ltd, Hamilton 3204, New Zealand
}

\section{Abstract}

Background/Objectives: Water mains are part of a drainage network that generally supplies fresh water to the households within council (municipal) limits. Most councils set a benchmark minimum water pressure $(\mathrm{kPa})$ and a flow rate $(1 / \mathrm{min})$ that must be delivered to households. A typical drainage network may consist of straight pipe with different bends, reducers, expansions and several fittings, all of which contribute to loss of pressure in the fluid system. The main objective of this paper is to compare different gradients of reducers using Applied Computational Modelling techniques. This comparison is performed in terms of pressure drop across the section, the total pressure on the reducing face and regular forces on the inner face of each reducer on two types of reducers, i.e. Concentric and Eccentric. Methods: In this paper, computational analyses using CFD tools are applied to a pipe from a typical water mains line consisting of a concentric reducer that generally holds a certain amount of pressure. Comparison between different gradients of reducing face of both concentric and eccentric reducers has been performed in terms of pressure drop across the section, the total pressure on the reducing face and normal forces on the inner face of each reducer. Polyethylene (PE) stub flanges and galvanized backing rings are attached to the pipe. The material properties for the pipe and the reducer are set to high-density polyethylene (HDPE), and they are butt-welded together. The simulation and analysis are performed using SOLIDWORKS-CFD/FE software. Findings: The simulation results show the predicted flow trajectories of the fluid flowing through both reducers depicting difference in flow trajectories and their consequent effect on fluid system and the system's structure in terms of Pressure drop, water force etc. when the reduction is changed from concentric to eccentric. Applications: The quantified flow simulation is used to optimize the section design according to the dynamic pressure head required. The results show that the optimized reducer serves better than conventional reducers.

Keywords: Water main; computational fluid dynamics; concentric and eccentric reducers 


\section{Introduction}

Head pressure is the force that pushes water through pipes. Most councils set a benchmark minimum water pressure $(\mathrm{kPa})$ and a flow rate $(1 / \mathrm{min})$ that must be delivered to households. For example, Watercare which manages water distribution in the Auckland region of New Zealand, maintains a minimum head pressure of $200 \mathrm{kPa}$ and a flow rate of $25(\mathrm{l} / \mathrm{min})^{(1)}$. Consequently, Watercare advises households that before installing any flow-restricting devices or low-flow showerheads, they must install a hot water cylinder with mains (equal) water pressure or low (unequal) water pressure ${ }^{(1)}$. This is necessary because some flowrestricting devices and low-flow showerheads are not compatible with a hot water cylinder with low (unequal) water pressure. Conversely, Hamilton City Council, which provides water distribution for the Hamilton region acknowledges that the water pressure varies around the city and depends mainly on where the property is located ${ }^{(2)}$. For example, the central business district has up to 92 meters of head ( $901.98 \mathrm{kPa}$ of head pressure) whereas other areas have a minimum of 10 meters' head (head pressure of $100 \mathrm{kPa}$ ). The council states that each house has a flow rate of $25(\mathrm{l} / \mathrm{min})$ available. Auckland's water derives mainly from dams and an aquifer, with a (limited term) back-up arrangement to draw from the Waikato river ${ }^{(3)}$. Hamilton's water supply comes from the Waikato River ${ }^{(2)}$.

This could be to the fast population growths in Auckland, and therefore, there is a high demand for a high dynamic pressure head to households and other facilities. This only means that Auckland council surely has to have much more powerful water systems than Hamilton council, which means either use of bigger pumping facilities (which use more energy) or use of smarter line systems (with lower minor head loss due to fittings) minimizing overall head losses.

The literature reveals that many cities worldwide face issues with delivering sufficient water to a growing number of households and businesses and are seeking solutions to maintain a sustainable supply of water reach to each household ${ }^{(4-7)}$. Unfortunately, freshwater is often wasted in the delivery process due to deficient infrastructure: it is estimated that leakage from pipes causes more than 32 billion cubic meters of water, annually, to be wasted from water mains worldwide ${ }^{(8)}$. Greater demand distributes the water flow further. For example, in crowded cities such as Hong Kong, residents consume around $1200 \mathrm{Mm} 3$ year-1 (i.e. the per capita daily consumption is $408 \mathrm{~L}$ day-1) of water annually, and this amount will grow to $1315 \mathrm{Mm} 3$ year-1 in $2030^{(8)}$. All of these issues will reduce the dynamic pressure head delivered to each household.

Computational modelling techniques are reliable tools to estimate pressure drop and understand nonidealities in pipe fittings ${ }^{(9)}$. Therefore, we are using computational analyses using CFD tools are applied to a section of pipe system from a typical water mains line consisting of a concentric reducer that generally holds a certain amount of pressure. Comparison between different gradients of both concentric and eccentric reducers is performed in terms of pressure drop across the section, the total pressure on the reducing face and regular forces on the inner face of each reducer. This helps designers better understand the difference a little extra gradient can make in terms of pressure drop, the effect a sudden contraction can cause in the system and how we can reduce the adverse effects by switching from eccentric to concentric reducers where possible and by using gradual contraction instead of sudden contraction in the system.

In terms of mechanical engineering, the force that acts on the reducing face parallel to the flow line dictates the shear force acting on the adjacent butt weld, and the CFD simulations show the difference in the water force that acts on higher and lower gradients of the same reducing face. All of this adds up to minimizing the head drop to the end user and a better overall water delivery system.

\section{Design and material properties}

The proposed designs are shown in Figure 1 (b) and (d). They illustrate the assembly for the pipe with concentric and eccentric reducers, respectively, along with the stub flange and Galvanized Backing Ring. The Figures show the section of the system representing a reduction of pipe size from DN300 to DN200. The larger pipe with polyethylene material properties is the DN300 setup, which has an OD of $315 \mathrm{~mm}$ whilst the smaller side has a DN200 pipe with an OD of $200 \mathrm{~mm}$. The pressure rating of the pipe is PN16, which means the section can hold 16 bar of pressure. The fitting reducers are also set with a PN16 rating and are made from Polyethylene (PE) in four different designs: Concentric; Concentric KB-Optimized reducer; Eccentric; and Eccentric KB-Optimized reducer. 


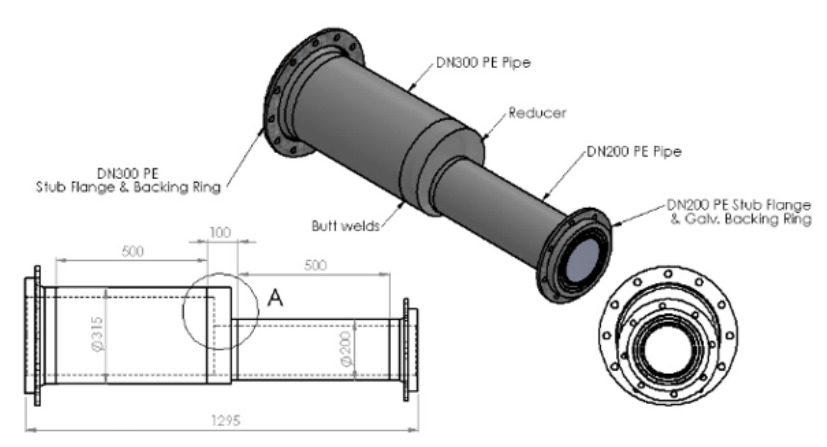

(a)

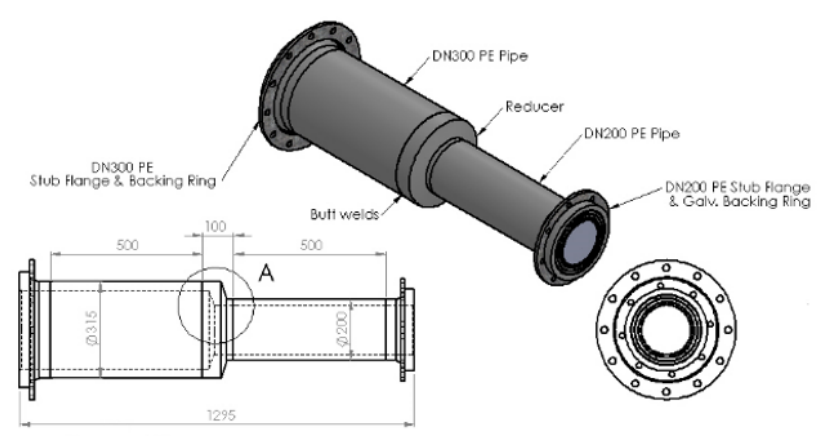

(c)

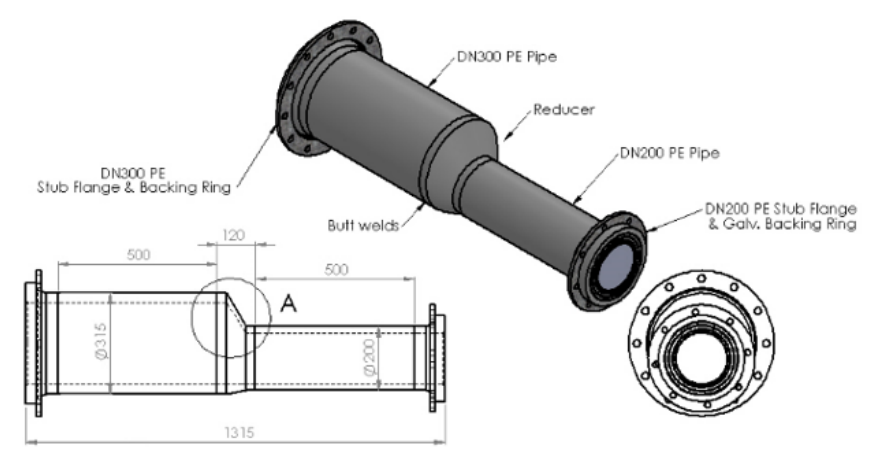

(b)

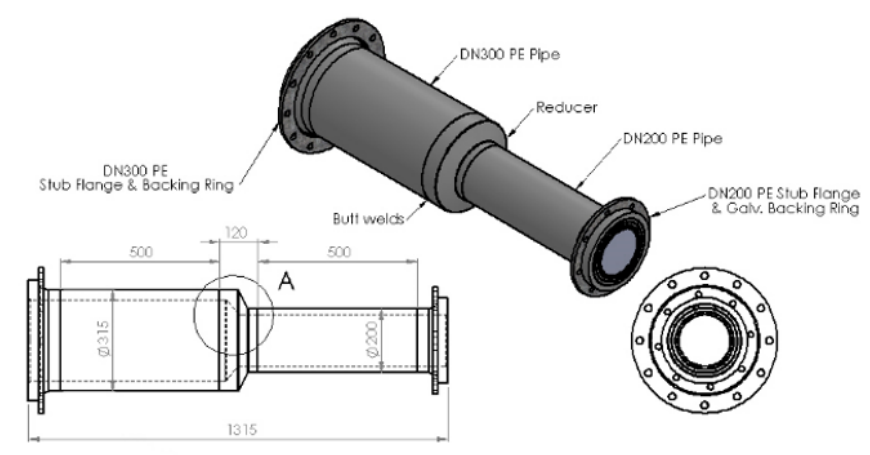

(d)

Fig 1. Section details for (a) Eccentric reducer; (b) Eccentric reducer kB; (c) Concentric reducer; and (d) Concentric reducer kB.

The Stub-flanges are butt-welded to the PE pipes and are also rated to PN16 and constructed of PE materials. The Backing Rings are in two different sizes used on both ends of the section. These rings are bolted onto the rest of the system, and they are set to Galvanized materials. The mechanical Material properties for the PE and Galvanized steel are shown in Table 1.

Table 1. Material properties for PE and galvanized steel.

\begin{tabular}{lll}
\hline Material & PE high density & Galvanized Steel \\
\hline Tensile Strength $(\mathrm{MPa})$ & 22.1 & 356.9 \\
Young's Modulus $(\mathrm{GPa})$ & 1.07 & 200 \\
Poisson's ratio & 0.41 & 0.29 \\
Shear Modulus $(\mathrm{GPa})$ & 0.3772 & $\mathrm{NA}$ \\
Density $(\mathrm{kg} / \mathrm{m} 3)$ & 952 & 7870 \\
\hline
\end{tabular}

The PE parts are butt-welded together hence are considered "bonded" in the CFD analysis, which will treat it as though they are welded in its analysis. The backing rings are to be bolted to the system from which the section is taken. The connection between the backing ring and the stub flange is to be taken as "no penetration" in CFD analysis, which means the backing ring is pressed against the back face of the stub flange but the materials do not penetrate each other.

A mixed flow of laminar and turbulent nature is used for the CFD analysis and their subsequent forces are taken into account in the FEA static analysis. The fluid properties for water, dynamic viscosity (0.001002 Pa.s) and the density (1000 kg/m3), are taken into account. 


\section{Computational domain and mesh generation}

All the parts have been created using SOLIDWORKS and the following settings were set for the simulation within the wizard setup: analysis type is set as an internal flow with adiabatic wall; flow type is set to Laminar and Turbulent; water is the default fluid; the roughness value is 3 micrometres; and initial conditions are set to atmospheric pressure and temperature of 101.325 $\mathrm{kPa}$ and $293.2 \mathrm{k}$, respectively.

The conservation laws for mass, angular momentum and energy in the cartesian coordinate system rotating with angular velocity $\Omega$ about an axis passing through the coordinate system's origin using the following Equations:

$$
\begin{gathered}
\frac{\partial \rho}{\partial t}+\frac{\partial}{\partial x_{i}}\left(\rho u_{i}\right)=0 \\
\frac{\partial \rho u_{i}}{\partial t}+\frac{\partial}{\partial x_{j}}\left(\rho u_{i} u_{j}\right)+\frac{\partial p}{\partial x_{i}}=\frac{\partial}{\partial x_{j}}\left(\tau_{i j}+\tau_{i j}^{R}\right)+S_{i} i=1,2,3
\end{gathered}
$$

Where $u$ is the fluid velocity, $\rho$ is the fluid density, $S_{i}$ is a mass-distributed external force per unit mass due to a porous media resistance.

In this study, we used the laminar/turbulent boundary layer model using the Direct Numerical Simulation (DNS) which describes in near-wall regions and investigates the transitions from laminar to turbulent flow and vice versa using Van Driest's profile.

Setting the inner face of the outlet lid as static pressure opening as outlet boundary condition (as shown in Figure 2 ) and the inlet boundary conditions with an arbitrary volume flow rate through the inlet lid to $25 \mathrm{l} / \mathrm{min}$, in accordance with the Hamilton Council and Auckland Watercare flow conditions. Setting goals to define the project inlet, outlet average pressure and average velocity on inner faces of respective lids conditions. We set up an equation goal to calculate the total head loss:

$$
h_{\text {total }}=h_{f}+\sum h_{m}=\frac{P_{1}-P_{2}}{\rho g}+\frac{v_{1}^{2}-v_{2}^{2}}{2 g}
$$

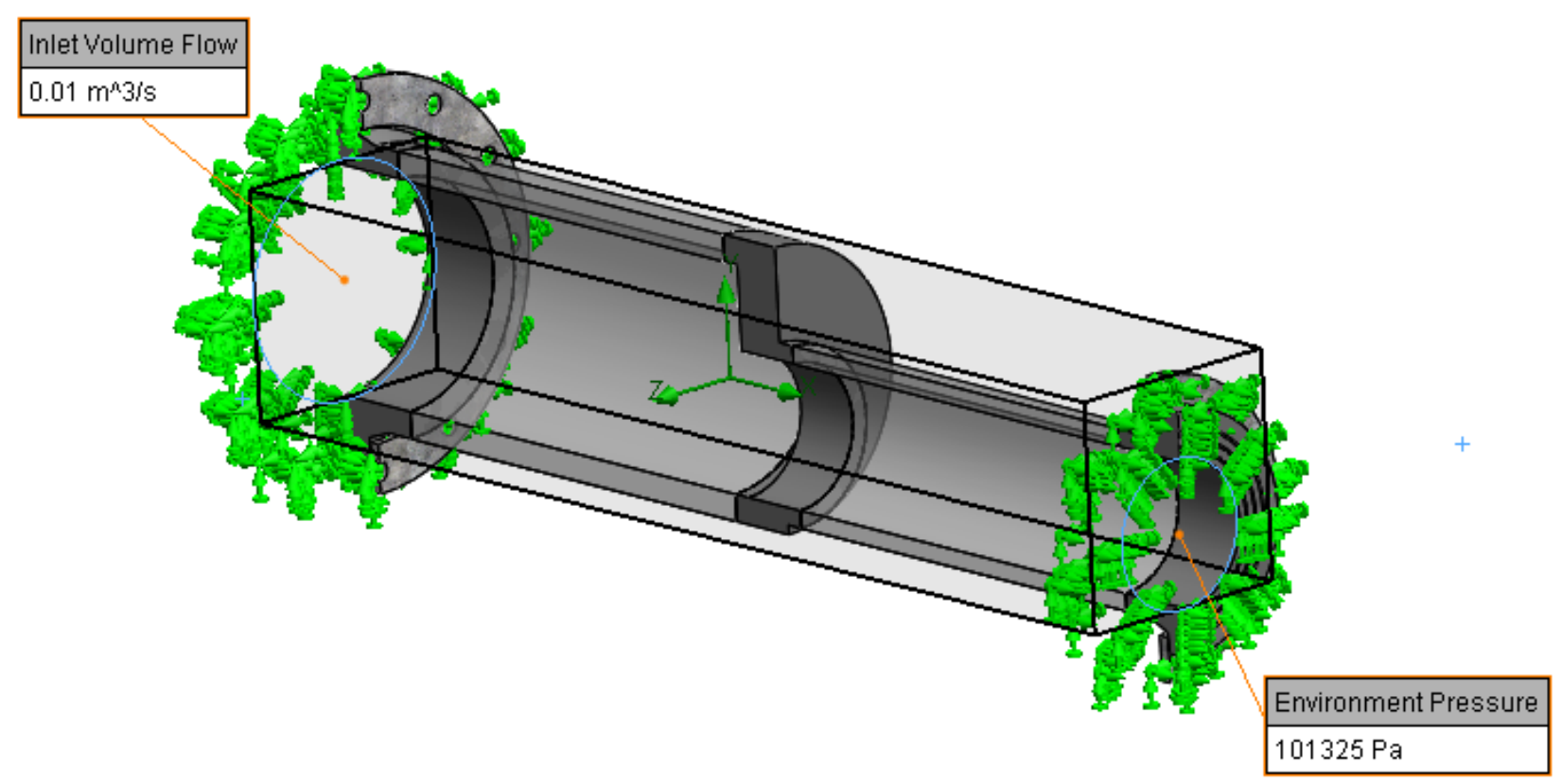

Fig 2. A symmetrical boundary conditions view to the model showing the inlet, outlet, fix ends and the fluid domain. 
This allows us to retrieve the head loss $\mathrm{h}_{\text {total }}$ value from the goal plot under the results. Then we set surface goals on the reducing face (where the fluid hits the reducer) for normal forces in all three directions, and force in the $\mathrm{x}$-direction. This will allow us to record and analyze visual results to predict flow patterns. We then export the CFD results to the FEA simulation. We fixed both ends of the pipe and set up a bonded-welded contact and no penetration (pushed together but there is no bond between stub flange and backing with the DN300 and the Galvanized backing ring with the DN200 PE pipe). The SOLIDWORKS flow simulation solves the governing equations with a discrete numerical technique based on the finite volume (FV) method. A cartesian rectangular coordinate system is used in our models. The mesh details depicted by SOLIDWORKS are as follows: total nodes (23731), total elements (11973), Maximum Aspect Ratio (21.89) and \% of elements with Aspect Ratio $<3$ is 85.8 as shown in Figure 3. To achieve an acceptable grid independency, the simulation was repeated for a different number of elements until the grid independencies were achieved.

Reducer assembly Concentric KB
Int

Model name:Reducer assembly Study name:Concentric KB Static-Concentric KB-J Mesh type: Solid Mesh

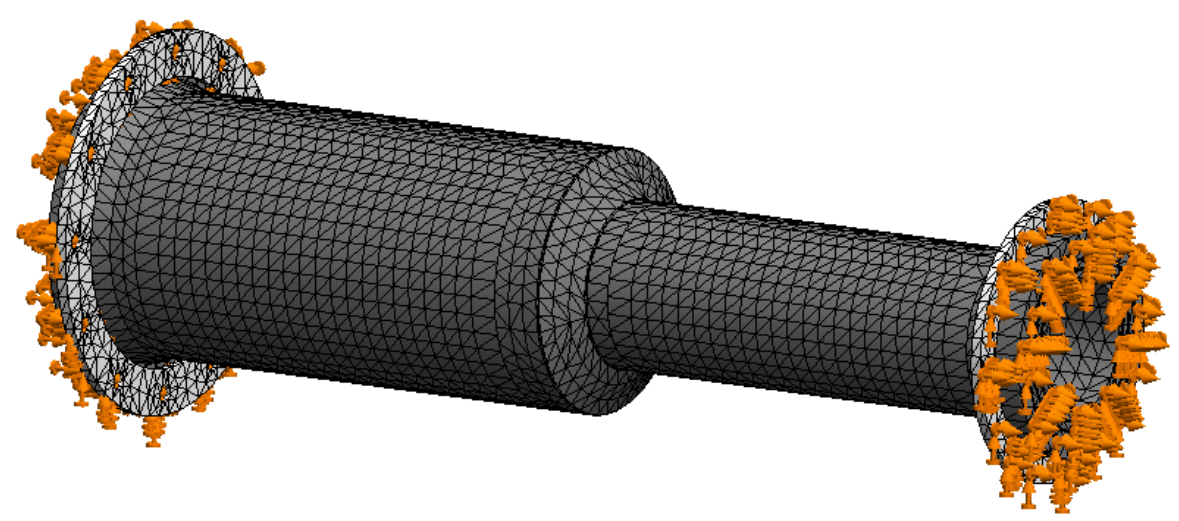

Fig 3. Mesh generation for the concentric KB design for FE analysis.

\section{Results and discussion}

The results obtained from SOLIDWORKS for the FE analysis provide the max and min load Von Mises stress values, as shown in Figure 4 . This Figure illustrates the critical areas for the materials to yield or fracture. The eccentric KB design shows the most significant promise in terms of reducing the likelihood of fracture compared to the standard eccentric reducer. All the reducers are further investigated as to their performance in terms of flow velocity. 


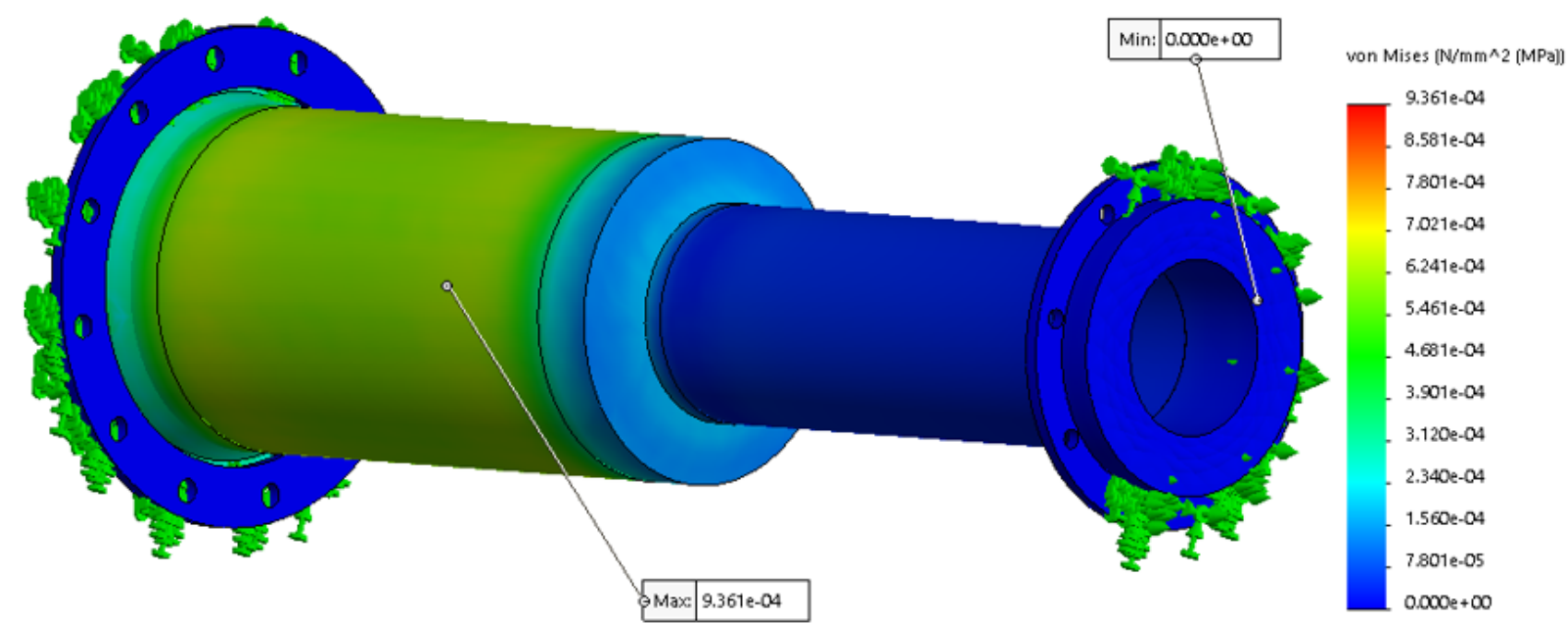

(a)

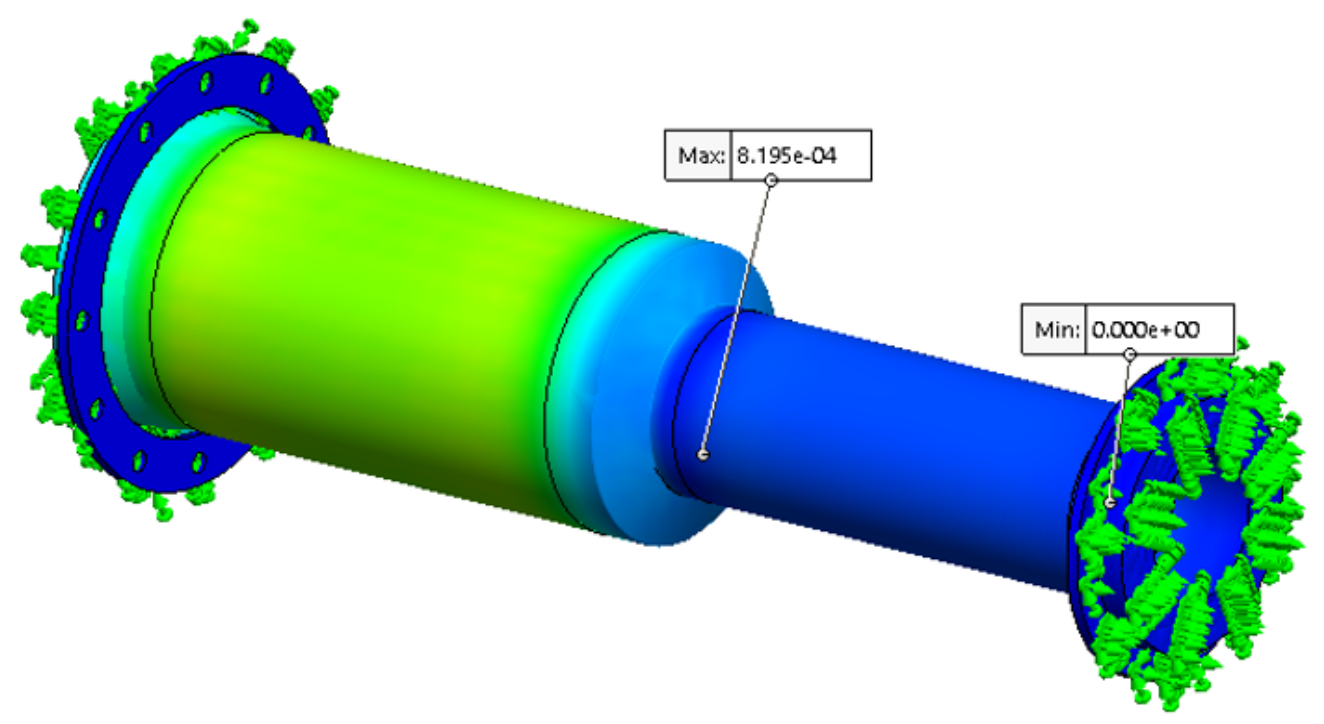

(b) 


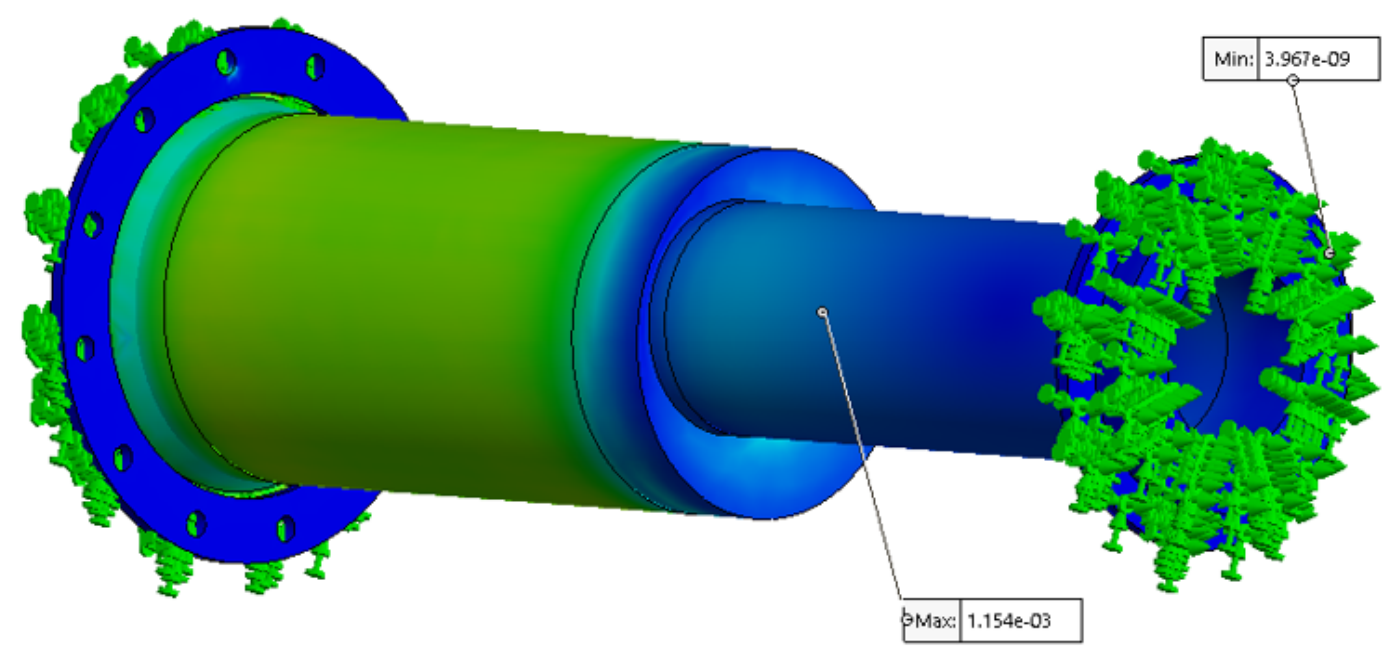

von Mises (N/mm^2 (MPa))

(c)

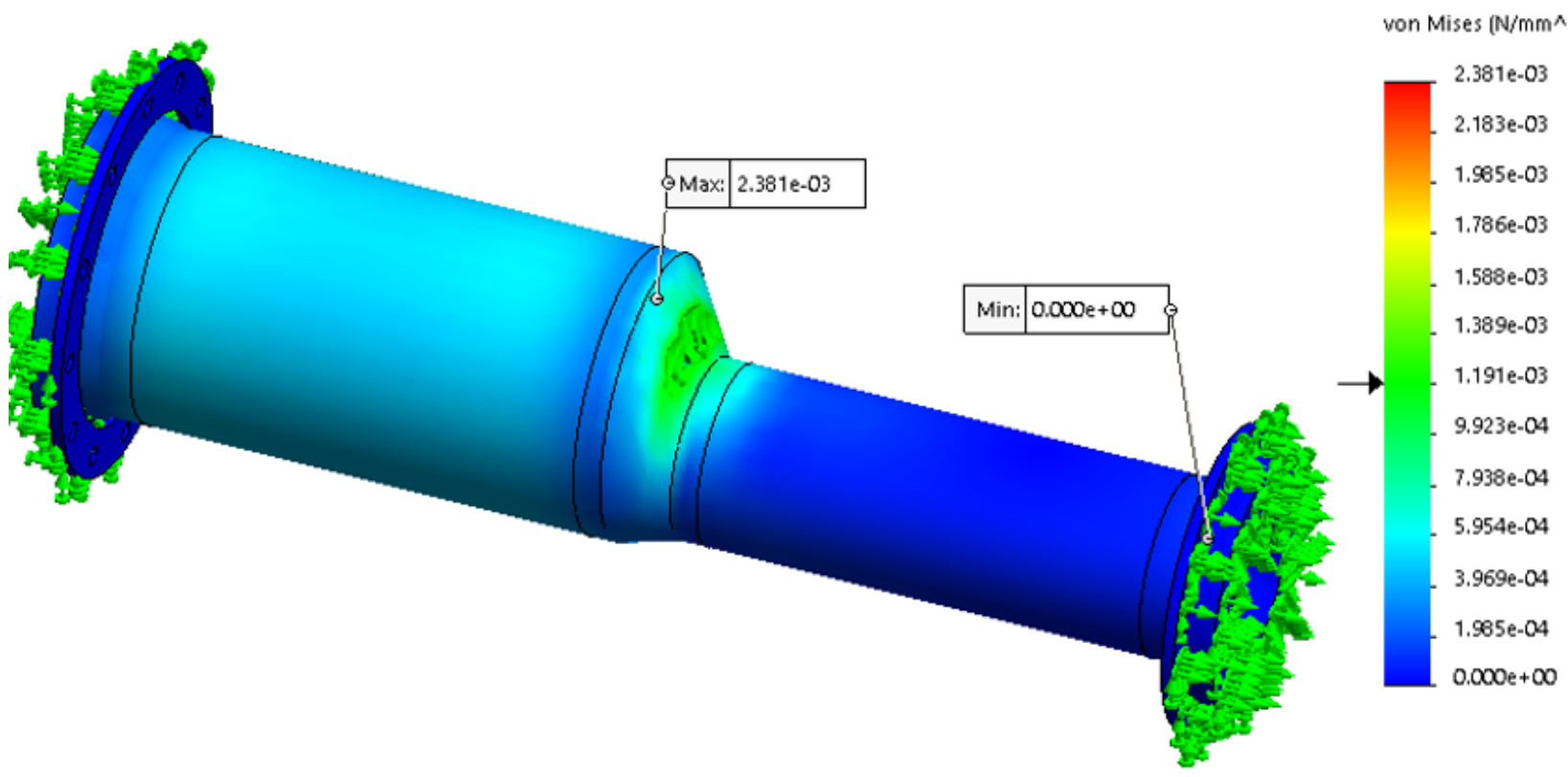

(d)

Fig 4. Von Mises Stress analysis; (a) Reducerassembly-Concentric; (b) Reducer assembly-Concentric KB (c) Reducerassembly-Eccentric; and (d) Reducer assembly-Eccentric KB.

Figure 5 shows the velocity profile for the four different CFD simulated designs. The results for the eccentric $\mathrm{kB}$ reducer supports the outcome for Figure 4 : this design is best for handling dynamic pressure. 


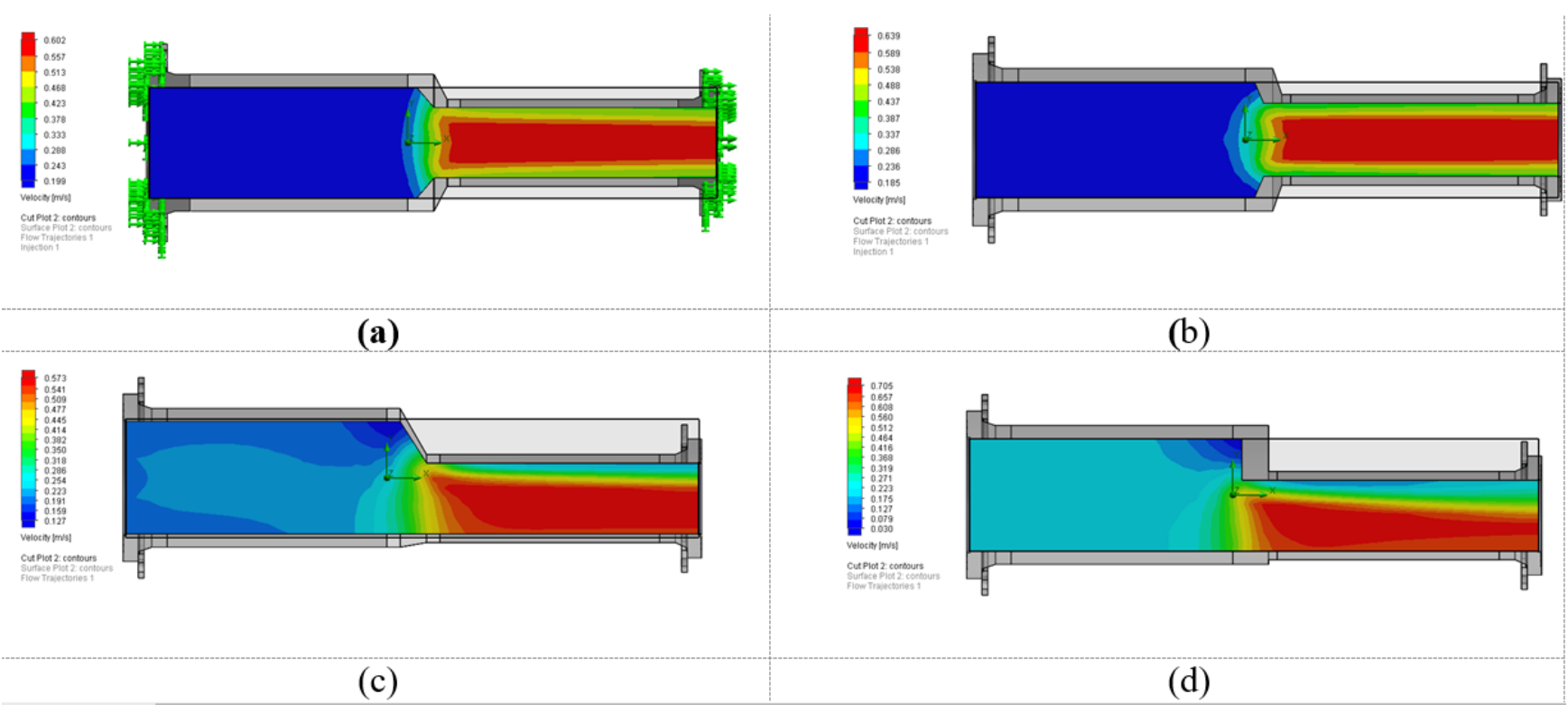

Fig 5. Velocity analysis for the four designs using CFD (a) Reducer assembly-Concentric KB; (b)Reducer assembly-Concentric; (c) Reducer assembly-Eccentric KB and (d) Reducerassembly-Eccentric

The main aim of this research is to reduce the impact for (force in $\mathrm{x}$-direction) on the reducing face of the reducer to avoid leakages. The optimized reducers produced many outcomes based on our goal plots setup as shown in Tables 2 and 3 .

Table 2. Result comparison for concentric type reducers $\mathrm{kB}$.

\begin{tabular}{llll}
\hline Goal Name & Unit & Concentric & Concentric KB -Optimized \\
\hline SG Av Total Pressure Inlet & {$[\mathrm{Pa}]$} & 101524.44 & 101495.79 \\
SG Av Velocity Inlet & {$[\mathrm{m} / \mathrm{s}]$} & 0.200 & 0.200 \\
SG Av Total Pressure Outlet & {$[\mathrm{Pa}]$} & 101453.46 & 101452.13 \\
SG Av Velocity Outlet & {$[\mathrm{m} / \mathrm{s}]$} & 0.49 & 0.49 \\
SG Av Total Pressure Reducing face & {$[\mathrm{Pa}]$} & 101500.64 & 101462.20 \\
SG Normal Force (X) Reducing face & {$[\mathrm{N}]$} & 5.25 & 3.95 \\
SG Normal Force (Y) Reducing face & {$[\mathrm{N}]$} & 0.000638 & -0.000378 \\
SG Normal Force (Z) Reducing face & {$[\mathrm{N}]$} & -0.001669 & -0.002847 \\
SG Force (X) 1 & {$[\mathrm{N}]$} & 5.26 & 3.96 \\
Pressure head difference & {$[\mathrm{m}]$} & 0.0072 & 0.0044 \\
Velocity head difference & {$[\mathrm{m}]$} & -0.0105 & -0.0105 \\
Head Loss & {$[\mathrm{m}]$} & -0.0033 & -0.0060 \\
\hline
\end{tabular}

Tables 2 and 3 show the force acting in thex-direction, or the normal force on the reducing force, is decreased by using the optimized reducer. Less force on the reducing face will exert less parting force on the weld that bonds the reducer to the straight pipe, this means less chance of weld failure which is the ultimate goal in reducing leakage. This agrees with Figure 5, which shows the velocity distributions with a smoother transition which directly relates to the system stability.

A reduction is identified in Von Mises stress by using the optimized reducer which ensures the safety of system. An easier transition of cross section, in the concentric reducer's case, helps the fluid glide across the system and decreases normal forces exerted by the fluid onto the system walls. 
Table 3. Result comparison for Eccentric type reducers kB.

\begin{tabular}{llll}
\hline Goal Name & Unit & Eccentric & Eccentric KB -Optimized \\
\hline SG Av Total Pressure Inlet & {$[\mathrm{Pa}]$} & 101556.41 & 101488.24 \\
SG Av Velocity Inlet & {$[\mathrm{m} / \mathrm{s}]$} & 0.200 & 0.200 \\
SG Av Total Pressure Outlet & {$[\mathrm{Pa}]$} & 101458.46 & 101454.52 \\
SG Av Velocity Outlet & {$[\mathrm{m} / \mathrm{s}]$} & 0.497 & 0.498 \\
SG Av Total Pressure Reducing face & {$[\mathrm{Pa}]$} & 101540.64 & 101440.35 \\
SG Normal Force (X) Reducing face & {$[\mathrm{N}]$} & 6.51 & 3.51 \\
SG Normal Force (Y) Reducing face & {$[\mathrm{N}]$} & $-1.85685 \mathrm{E}-17$ & 0.372039604 \\
SG Normal Force (Z) Reducing face & {$[\mathrm{N}]$} & $1.0276 \mathrm{E}-16$ & -0.001383421 \\
SG Force (X) 1 & {$[\mathrm{N}]$} & 6.51 & 3.54 \\
Pressure head difference & {$[\mathrm{m}]$} & 0.009984 & 0.003437 \\
Velocity head difference & {$[\mathrm{m}]$} & -0.010582 & -0.010630 \\
Head Loss & {$[\mathrm{m}]$} & -0.000598 & -0.007193 \\
\hline
\end{tabular}

But an increment is noted in all three results for eccentric reducer optimization. These stresses are noted at two different locations; that is, the location of the max stress is different in both cases. This means, with the optimized reducer, the stress concentration is changed to the reducing face, which is further away from the weak point of the assembly which is at the weld between the reducer and the straight pipe. It still enhances the system and the fluid flow is much smoother, as shown in Figure 6 . This figure shows the pressure and velocity distributions for the eccentric kB reducer. Also, from Figure $6 \mathrm{~b}$ shows a very smooth velocity streamlines, which means fewer vortexes developed at the eccentric reducer. Since the eccentric reducer has a much larger surface to counter the water forces in $\mathrm{x}$-direction hence the most significant reduction in forces out of all the iterations, Eccentric KB showed the best results. However, all the iterations showed that the gradual reduction in size of the pipeline, better the results in terms of forces acting on the reducing face and better the flow trajectories of the system.

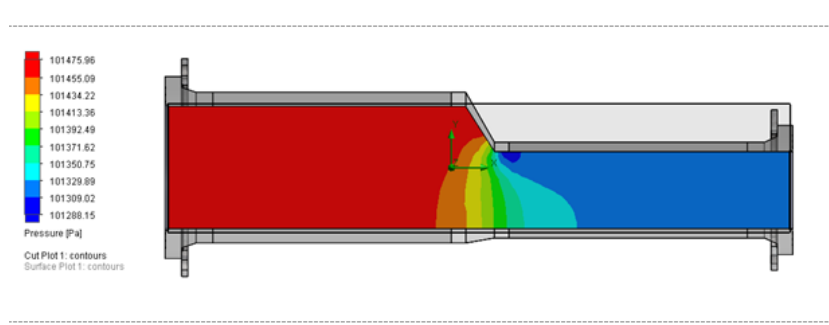

(a)

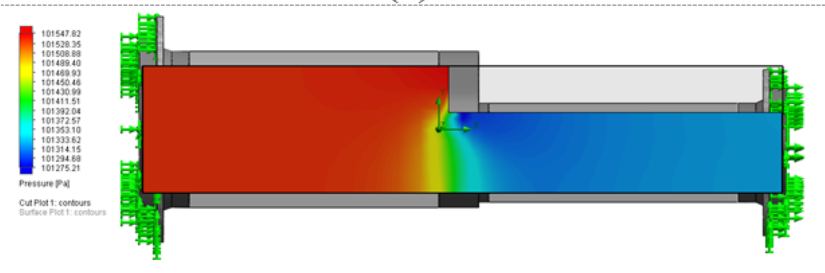

(c)

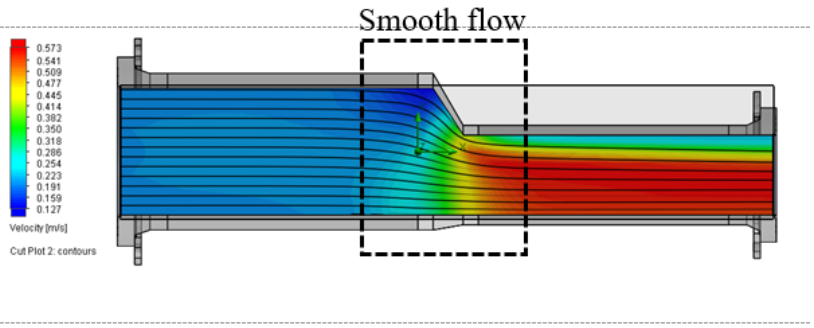

(b)
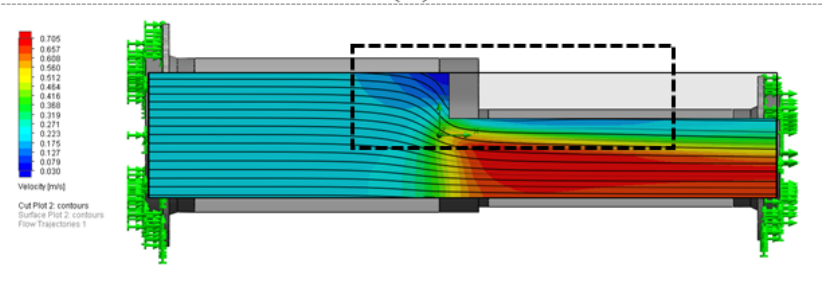

(d)

Fig 6. Pressure and velocity contours for the Eccentric kB and Eccentric reducers; (a) pressure contours for Eccentric kB, (b) velocity streamline for Eccentric $\mathrm{kB}$, (c) pressure contours for Eccentric $\mathrm{kB}$ and (d) velocity streamline for Eccentric.

Additionally, we set up a probe sensor on both the reducers to check the reduction in stress for the eccentric KB reducer as shown in Figure 7.

Overall, there is head gain noted in both the optimization scenarios. CFD and FEA for normal reducers showed the stress locations being near the weld which can cause weld failure whereas the stress locations for optimized reducers show the concentration is away from the weld, which is favored for system stability. 


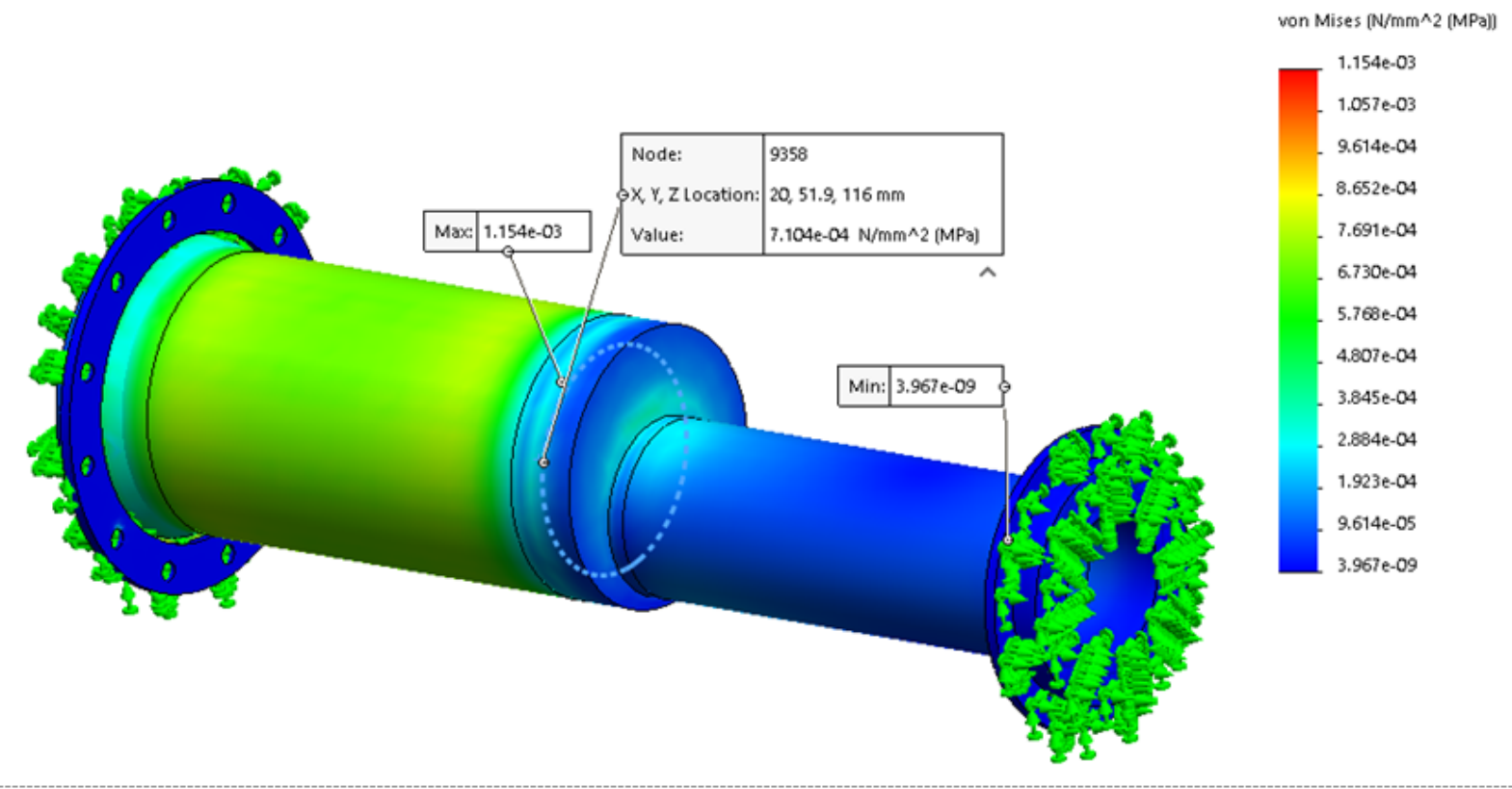

(a)

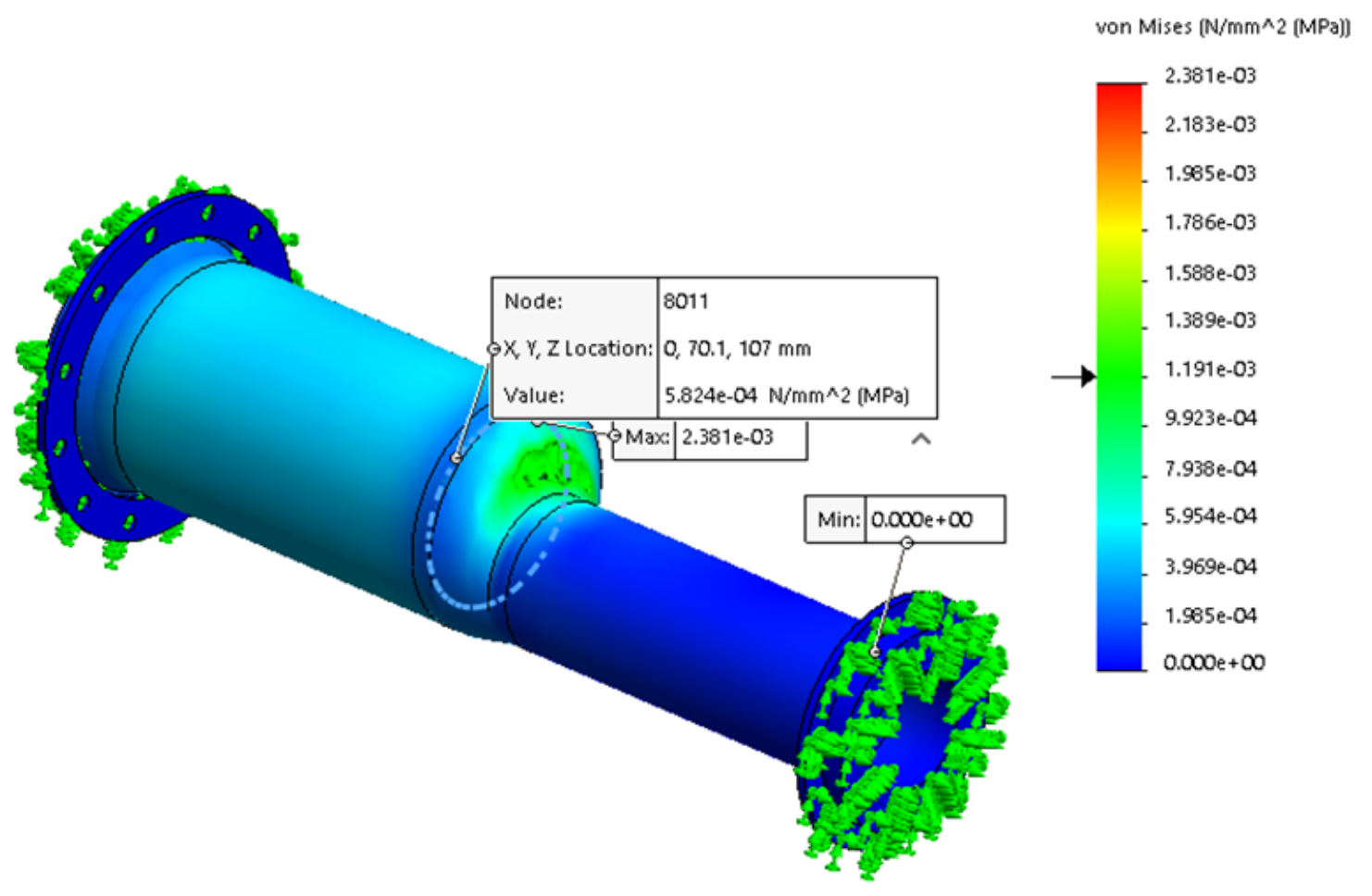

(b)

Fig 7. Probe sensor for max stress for eccentric reducers; (a) Probe sensor result for eccentric reducer and (b) Probe sensor result for eccentric KB Optimized reducer.

One limitation of the models was the lack of options to include butt-welding in the system. The system is shown as different parts bonded together and considered as a perfect bond whereas in real life the weld is probably the weakest point, thus the 
most likely point where a system fails. Therefore, a safety factor should be applied to overcome any discrepancies.

Aside from that, the outcome of the study is in line with a general predicted behavior of a reducer e.g. stress concentration is recorded on the bigger side of reducers and higher velocity is recorded on the smaller side of the reducers.

\section{Conclusion}

In this article, computational fluid dynamic (CFD) analysis tools are used to compare the performing reducer from four designs, featuring standard concentric, concentric KB-optimized, standard eccentric, and eccentric KB-optimized reducers. Each reducer was constructed of high-density polyethylene (HDPE) material. Analyses were performed in terms of pressure drop across the section, the total pressure on the reducing face and the normal forces on the inner face of the reducer. The results of the CFD modelling could be used to adjust the section according to the system requirements. The Eccentric KB-Optimized reducer turned out to be the best design in terms of reducing the risk of fracture under different flow velocities. In addition, the results showed less force on the reducing face which exerted less parting force on the weld that bonds the reducer to the straight pipe, this means less chance of weld failure which is the ultimate goal in reducing leakage. Therefore, The Eccentric KBOptimized reducer served this function better than both types of concentric reducers, and the conventional eccentric reducer.

\section{Author Contributions}

Mohammad AL-Rawi and Chetan Sharma are the principle investigators for this project. They have contributed in writing the entire manuscript and the simulation. Hong Zhou is the partner for this project and he has provided scientific and technical interpretation of fluid dynamics.

\section{Conflict of Interest}

The authors declared no potential conflicts of interest with respect to the research, authorship, and publication of this article.

\section{References}

1) Watercare. (n.d.). New Zealand, Auckland-Watercare. . Available from: https://www.watercare.co.nz/Help-and-advice/Be-Waterwise/Pressure-and-flowrate.

2) Hamilton City Council.(n.d). New Zealand, Hamilton City Council, Water. . Available from: https://www.hamilton.govt.nz/our-services/water/water/ Pages/default.aspx.

3) Watercare. Watercare. (n.d.) Where your water comes from. . Available from: https://www.watercare.co.nz/Water-and-wastewater/Where-your-watercomes-from.

4) Rossi M, Nigro A, Renzi M. Experimental and numerical assessment of a methodology for performance prediction of Pumps-as-Turbines (PaTs) operating in off-design conditions. Applied Energy. 2019;248:555-566. Available from: https://dx.doi.org/10.1016/j.apenergy.2019.04.123.

5) Wang S, Cao T, Chen B. Urban energy-water nexus based on modified input-output analysis. 2017. Available from: https://doi.org/10.1016/j.apenergy. 2017.02.011.

6) U.S. Department of Energy. The water-energy nexus: challenges and opportunities. Washington DC: Department of Energy. 2014.

7) IEA (International Energy Agency). World energy outlook 2008. Paris: IEA/OECD. 2008.

8) Cheung CT, Mui KW, Wong LT. Energy efficiency of elevated water supply tanks for high-rise buildings. Applied Energy. 2013;103:685-691. Available from: https://dx.doi.org/10.1016/j.apenergy.2012.10.041.

9) Gajbhiye DB, Kulkarni AH, Tiwari SS, Mathpati CS. Teaching turbulent flow through pipe fittings using computational fluid dynamics approach. 2020. Available from: https://doi.org/10.1002/eng2.12093. 